
\title{
$\begin{array}{ll}\text { Research Square } & \text { Preprints are preliminary reports that have not undergone peer review. } \\ \text { They should not be considered conclusive, used to inform clinical practice, } \\ \text { or referenced by the media as validated information. }\end{array}$
}

\section{The Kebab Technique: Using a Bipolar Pencil to Retrieve a Dropped Nucleus via a Small Incision}

\author{
Hiroshi Aso ( $\square$ aso.hiroshi@nihon-u.ac.jp) \\ Nihon University Itabashi Hospital \\ Harumasa Yokota \\ Nihon University Itabashi Hospital \\ Hirotsugu Hanasaki \\ Nihon University Itabashi Hospital \\ Satoru Yamagami \\ Nihon University Itabashi Hospital \\ Taiji Nagaoka \\ Nihon University Itabashi Hospital
}

\section{Research Article}

Keywords: dropped nucleus, bipolar pencils, perfluorocarbon liquids (PFCL), best-corrected visual acuity (BCVA)

Posted Date: December 17th, 2020

DOI: https://doi.org/10.21203/rs.3.rs-127746/v1

License: (c) (i) This work is licensed under a Creative Commons Attribution 4.0 International License. Read Full License

Version of Record: A version of this preprint was published at Scientific Reports on April 12th, 2021. See the published version at https://doi.org/10.1038/s41598-021-87022-3. 


\section{Abstract}

We developed a new method to retrieve a dropped nucleus via a small incision using bipolar pencils, the kebab technique, to solve the lack of small-gauge fragmatomes, and the expense and toxicity of perfluorocarbon liquids (PFCL). A total of 8 eyes in 6 patients underwent this technique and were reviewed. After vitrectomy, the dropped nucleus was lifted from the retina by adhesion with a bipolar pencil, and phacoemulsification was performed while rotating the lens. The outcome measures were best-corrected visual acuity (BCVA), intraocular pressure (IOP), and corneal endothelial cell density before and after surgery. Surgical indications included zonular weakness, trauma, acute angle closure attack, and phacolytic glaucoma. At 1 month, BCVA improved from a mean \pm SD $1.67 \operatorname{logMAR}( \pm 0.90)$ to $1.14 \log M A R( \pm 1.01)$. The mean preoperative intraocular pressure (IOP) was $24.5( \pm 16.8)$ $\mathrm{mmHg}$ and postoperative IOP was $11.0( \pm 2.8) \mathrm{mmHg}$. The mean preoperative corneal endothelial cell count was 2600 (322) cells $/ \mathrm{mm}^{2}$ (one eye was unmeasurable) and postoperative corneal endothelial cell count was $2387( \pm 431)$ cells $/ \mathrm{mm}^{2}$. There were no postoperative complications. The retrieval of a dropped nucleus using a bipolar pencil enables small incisions without using PFCL.

\section{Introduction}

Although recent advances in phacoemulsification apparatus have been improving surgical performance, the dropped nucleus is one of several intraoperative complications during cataract surgery that needs to be addressed. To preserve vision, the dropped nucleus must be removed while minimizing damage to the cornea, iris, and retina.

A fragmatome was previously used to emulsify and remove a nucleus in the vitreous with 20- and 23-gauge systems ${ }^{1}$. However, in the era of micro-incision vitrectomy surgery (MIVS) with 25- and 27-gauge systems, this device is too large to be used. Small fragments of the dropped nucleus can be safely removed with a small-gauge vitreous cutter, but it takes a long time to remove larger fragments because it is difficult to fix them, which risks damage to the macula.

Instead of these techniques, perfluorocarbon liquids (PFCL) are often used to float the dropped nucleus because of the advantages of avoiding retinal tearing and protecting the macula from fragments of the nucleus ${ }^{2-4}$. When the vitreous is filled with PFCL, the falling lens will rise to the iris plane, allowing the safe performance of phacoemulsification. However, PFCL is costly and residual PFCL in the vitreous may cause adverse effects ${ }^{5,6}$.

We have developed a new technique of lifting and fixing the dropped nucleus without using PFCL called the "kebab technique." This technique enables the operator to lift and fixed the dropped lens and to perform phacoemulsification safely in the anterior chamber or near the anterior vitreous in a method akin to shaving a rotating doner kebab.

\section{Results}

The characteristics of participants and postoperative outcomes are shown in Table 1. The study comprised 8 eyes of 6 patients (3 males and 3 females). The grades of nuclear sclerosis were grade 5 in 2 eyes, grade 4 in 3 eyes, and grade 3 in 3 eyes. The mean age at the time of surgery was $77.9( \pm 4.11) \mathrm{y}$. The indications for lens luxation or subluxation were zonular weakness in three eyes, trauma in two eyes, phacolytic glaucoma in two eyes, and acute angle closure attack in one eye. In six eyes, IOL implantation was performed with the Yamane double-needle intrascleral lens fixation technique. We inserted IOLs (AN6KA, Kowa, Tokyo) into four eyes and an X-70 (Santen, Osaka, Japan) into two eyes. In the two cases of phacolytic glaucoma, only lens removal was performed and IOL intrascleral fixation was not performed. In all eight consecutive cases, the bipolar pencil was firmly attached to the center of the nucleus by surface coagulation, allowing safe phacoemulsification. 
Table 1

The characteristics of participants and postoperative

outcomes

\begin{tabular}{|l|l|}
\hline & $\begin{array}{l}\text { Mean } \pm \text { SD } \\
8 \text { eyes of } 6 \text { patients }\end{array}$ \\
\hline Age $(\mathrm{y})$ & $77.9 \pm 4.11$ \\
\hline Sex & Males $(\mathrm{n}=3)$ Females $(\mathrm{n}=3)$ \\
\hline NS ${ }^{\mathrm{a}}$ & $3.88 \pm 0.78$ \\
\hline Axial Length & $23.13 \pm 0.40$ \\
\hline BCVA ${ }^{\text {b }}$ (logMAR) & \\
\hline Preop & $1.67 \pm 0.90$ \\
\hline Postop at 1month & $1.14 \pm 1.01$ \\
\hline IOPd & \\
\hline (mmHg) & $24.5 \pm 16.8$ \\
\hline Preop & $11.0 \pm 2.8$ \\
\hline Postop at 1month & \\
\hline Corneal endothelial & \\
\hline cell density (cells/mm ${ }^{2}$ ) & \\
\hline Preop & $2600 \pm 323$ \\
\hline Postop 1month & $2387 \pm 431$ \\
\hline aNS: Nuclear Sclerosis, IOL: Intraocular Lens, \\
\hline bCVA: best-corrected visual acuity \\
\hline d IOParithm of the minimum angle of resolution \\
\hline
\end{tabular}

Individual patient data are provided in Table 2. The mean axial length was $23.13(0.38) \mathrm{mm}$. BCVA improved from mean 1.67 $\log$ MAR (0.90) to $1.14 \log$ MAR (1.01) at 1 month after surgery. The mean ( \pm SD) preoperative intraocular pressure (IOP) was 24.5 $( \pm 16.8) \mathrm{mmHg}$ and postoperative IOP was $11.0( \pm 2.8) \mathrm{mmHg}$. The mean preoperative corneal endothelial cell density was $2600( \pm$ $322) \mathrm{cells} / \mathrm{mm}^{2}$ (one eye was unmeasurable) and the postoperative corneal endothelial cell density was $2387( \pm 431)$ cells $/ \mathrm{mm}^{2}$. No postoperative complications such as leakage, postoperative high or low intraocular pressure, vitreous hemorrhage, or retinal detachment occurred. 
Table 2

Individual patient data

\begin{tabular}{|c|c|c|c|c|c|c|c|c|c|c|c|}
\hline \multirow[b]{2}{*}{ Case } & \multirow[b]{2}{*}{ Age/Sex } & \multirow[b]{2}{*}{ Indication } & \multirow[b]{2}{*}{$N S^{d}$} & \multirow[b]{2}{*}{$\begin{array}{l}\text { Axial } \\
\text { length } \\
(\mathrm{mm})\end{array}$} & \multirow[b]{2}{*}{$\mathrm{IOL}^{\mathrm{e}}$} & \multicolumn{2}{|c|}{$\begin{array}{l}\text { BCVA }^{a} \\
\left(\log M A R^{b}\right)\end{array}$} & \multicolumn{2}{|c|}{ ' } & \multicolumn{2}{|c|}{$\begin{array}{l}\text { Endothelial cell density } \\
\left(\text { cells } / \mathrm{mm}^{2}\right)\end{array}$} \\
\hline & & & & & & Preop & $\begin{array}{l}\text { Postop } \\
\text { (1 } \\
\text { Month) }\end{array}$ & Preop & $\begin{array}{l}\text { Postop } \\
\text { (1 } \\
\text { Month) }\end{array}$ & Preop & $\begin{array}{l}\text { Postop } \\
\text { (1 } \\
\text { Month) }\end{array}$ \\
\hline 1 & $77 / F$ & $\begin{array}{l}\text { Phacolytic } \\
\text { glaucoma }\end{array}$ & 4 & 23.77 & None & 2.90 & 2.90 & 60 & 9 & 2494 & 1873 \\
\hline 2 & $78 / \mathrm{M}$ & $\begin{array}{l}\text { Acute } \\
\text { angle } \\
\text { closure } \\
\text { attack }\end{array}$ & 3 & 22.51 & AN6KA & 0.22 & 0.00 & 28 & 16 & 2110 & 2288 \\
\hline 3 & $74 / \mathrm{M}$ & Trauma & 3 & 23.31 & $x-70$ & 1.10 & 1.40 & 14 & 8 & 2825 & 3012 \\
\hline 4 & $74 / \mathrm{M}$ & Trauma & 3 & 23.22 & $x-70$ & 1.40 & 2.00 & 12 & 10 & 3205 & 2370 \\
\hline 5 & $72 / \mathrm{F}$ & $\begin{array}{l}\text { Phacolytic } \\
\text { glaucoma }\end{array}$ & 5 & 23.44 & None & 2.80 & 2.00 & 42 & 15 & Unmeasurable & 1613 \\
\hline 6 & $83 / F$ & $\begin{array}{l}\text { Zonular } \\
\text { weakness }\end{array}$ & 4 & 22.93 & AN6KA & 1.85 & 0.15 & 14 & 9 & 2410 & 2695 \\
\hline 7 & $83 / F$ & $\begin{array}{l}\text { Zonular } \\
\text { weakness }\end{array}$ & 4 & 22.62 & AN6KA & 0.80 & 0.30 & 17 & 12 & 2469 & 2545 \\
\hline 8 & $82 / \mathrm{M}$ & $\begin{array}{l}\text { Zonular } \\
\text { weakness }\end{array}$ & 5 & 23.21 & AN6KA & 2.30 & 0.40 & 9 & 9 & 2688 & 2703 \\
\hline
\end{tabular}

\section{Discussion}

A vitreous cutter can remove a dropped nucleus and its fragments with a low cut rate ${ }^{7}$. However, in processing hard nuclei, it is difficult to remove them only with a small-gauge vitreous cutter ${ }^{8}$. Other methods for retrieving a dropped nucleus have been reported by different operators. A fragmatome has been used to emulsify and remove a dropped nucleus in the vitreous, but it requires a special handpiece, and cannot be inserted through a small-gauge trocar, such as a 25-gauge or 27-gauge system. In previous reports, the incidence of postoperative retinal detachment after retained lens removal with a fragmatome combined with a 20-gauge system was $4 \%{ }^{9}$. Agarwal et al. ${ }^{10}$ and Chiang et al. ${ }^{11}$ performed a new levitating technique using a sleeveless phacotip. This technique has the advantage of not requiring special equipment such as a fragmatome, but requires a large 20-gauge pars plana wound. In addition, postoperative retinal cystoid macular edema (11\%) has also been reported with this method ${ }^{11}$. Currently, MIVS is mainly used for vitrectomy for retained lens fragments ${ }^{7}$. It is performed for dropped nuclei with a small-gauge trocar through a small incision ${ }^{12}$.

PFCL can be instilled to levitate and remove a dropped nucleus with a small-gauge trocar ${ }^{2-4}$. However, in addition to high costs, the residual PFCL has also corneal and retinal toxicities ${ }^{5,6}$. It is difficult to remove all residual PFCL globules from the vitreous. Subretinal PFCL is more difficult to remove ${ }^{13,14}$. Therefore, the kebab technique has the advantage of allowing phacoemulsification without PFCL in the anterior chamber. By bonding the tip of the bipolar pencil to the center of the dropped nucleus, the lens can be reliably lifted and can undergo phacoemulsification in a safe position.

We initially tried needles and forceps to lift the dropped lens. There was a risk that the needle would damage the retina. With a blunt tip, forceps could safely penetrate without any risk of deeply damaging the retina. However, it is impossible to synchronize the hand with the penetrated nucleus using a blunt tip and forceps because the contact between the lens nucleus and the shaft of 
the forceps is not sufficient to fix the lens. Therefore, we developed this method of bonding the shaft and the nucleus with the aid of a bipolar pencil.

The advantage of this method using a bipolar pencil is that the tip of the bipolar pencil and the nucleus can be completely bonded by coagulation. Thereby, the lifted nucleus can undergo phacoemulsification with its rotation completely controlled. Since the nucleus is emulsified at a position away from the cornea and retina, even with severe nuclear sclerosis as in our cases, there were no complications. In addition, we can perform this technique even in cases of poor mydriasis (Fig. 1) with a small incision. Therefore, it is possible to remove the nucleus and affix the IOL without any suturing by applying the Yamane double-needle technique ${ }^{15}$. The disadvantage of the kebab method is that some nuclear fragments may fall into the vitreous. By performing phacoemulsification like shaving doner kebab, the lifted nucleus can be removed without dropping a large fragment into the vitreous. The small dropped nuclear fragments can be easily removed with a low-cut-rate vitreous cutter in cases where the nuclear grade is low. If the patients have a hard nucleus (grade 4-5), the nuclear fragments can be completely removed using the kebab technique.

In conclusion, we introduce a new method, the so-called "kebab technique," to retrieve a dropped nucleus without using PFCL, through a small incision. Further studies with a larger number of patients will be required to confirm the improvement in safety and optimize our procedure.

\section{Methods}

The study protocol, approved by the Institutional Review Board of the Nihon University School of Medicine (approval number: RK190611-1), adhered to the tenets of the Declaration of Helsinki. Written informed consent was obtained from all participants. All surgeries were performed by a single surgeon $(\mathrm{AH})$ at the Division of Ophthalmology, Department of Visual Sciences, Nihon University School of Medicine between January 2018 and March 2019. We reviewed cases, mostly of trauma, where nuclei had been dropped before surgery, as well as cases of luxation/subluxation with dropped nuclei during surgery. All patients underwent a standard ophthalmologic examination, including best-corrected visual acuity (BCVA), slit lamp examination, measurement of intraocular pressure (IOP), and corneal endothelial cell density before and after surgery. Progression of nuclear sclerosis was based on the Emery-Little classification, which was graded by another ophthalmologist (TN) blinded to the type of surgery. BCVA was converted from the Landolt chart at $5 \mathrm{~m}$ to the logarithm of the minimum angle of resolution (logMAR) ${ }^{16}$. Counting fingers (CF) was defined as $1.85 \log M A R$, hand motion (HM) as $2.3 \log M A R{ }^{17}$, light perception (LP) as 2.8 logMAR, and no light perception (NLP) as $2.9 \log \mathrm{MAR}^{18}$.

\section{Surgical technique (kebab technique)}

Under peribulbar anesthesia, a 25-gauge pars plana vitrectomy was performed using a Constellation Vision System (Alcon Laboratories, Inc., Fort Worth, TX). First, the vitreous around the dropped nucleus was removed. A 2.4-mm incision for phacoemulsification and aspiration (PEA) was made at the 12 to 1 o'clock position after anterior and posterior vitrectomy. We used a bipolar pencil (SR-14-5000-10, Kirwan, Marshfield, MA) introduced via the trocar cannula system to fix the dropped nucleus by surface coagulation and to lift it into the anterior chamber. The diathermic power was set to approximately $50 \%$.

The first step of this procedure was to place the tip of the bipolar pencil close to the dropped nucleus (Fig. 2a). When the tip of the bipolar pencil lightly touched the nucleus slightly, surface coagulation was immediately performed for a brief time until the tip stuck to the center of the nucleus (Fig. 2b). The dropped nucleus affixed to the bipolar pencil was then gently lifted up from the retina.

The second step was to fix the nucleus more firmly to the tip of the bipolar pencil. The bonded bipolar pencil recoagulated the lifted nucleus assisted by an endoilluminator (Fig. 2c). When the tip of the bipolar pencil reached the center of the nucleus, the bond became stronger and the nucleus could be fully controlled by the bipolar pencil (Fig. 2d).

The third step was to subject the lifted nucleus to PEA. While lifting the nucleus to the anterior chamber, the phaco probe was inserted. We could rotate the bonded nucleus by turning the bipolar pencil without moving the phaco probe in the anterior chamber (Fig. 2e), allowing the nucleus to be shaved. If some nucleus fragments fell into the vitreous, they were removed after PEA with a 
25-gauge vitreous cutter with a low cut rate, 500 to 1,000 cycles per minute. If necessary, the intraocular lens (IOL) was affixed by the Yamane double-needle intrascleral lens fixation technique (Fig. 2f), which is described in detail elsewhere ${ }^{15}$. In brief, an angled sclerotomy was made with a 30-gauge thin-wall needle, $1.5 \mathrm{~mm}$ from the limbus. The haptics were not cut before using the cautery device. The incision was expanded to $2.8 \mathrm{~mm}$ before IOL insertion.

We measured corneal endothelial cell density using Konan NSP 9900囚 specular microscopy (Konan Medical Inc., Nishinomiya, Japan) before and 1 month after surgery.

\section{Declarations}

\section{Acknowledgements}

None.

\section{Author contributions statement}

H.A. and S.Y. conceived the study design. H.A performed and H.Y. and H.H. assisted the surgeries. H.A., H.Y. and wrote the manuscript. S.Y. and T.N. provided critical revision to the article. All authors reviewed the manuscript.

\section{References}

1. Wallace RT, McNamara JA, Brown G, Benson W, Belmont J, Goldberg R, Federman J. The use of perfluorophenanthrene in the removal of intravitreal lens fragments. Am J Ophthalmol 116:196-200(1993).

2. Watanabe A, Gekka T, Tsuneoka H. Treatment of a dislocated lens by transcorneal vitrectomy and bimanual phacoemulsification. Clin Ophthalmol 8:1539-1542(2014).

3. Lee SJ, Kim IG, Park JM. Management of posteriorly dislocated crystalline lens with perfluorocarbon liquid and fibrin glueassisted scleral-fixated intraocular lens implantation. J Cataract Refract Surg 39:334-338(2013).

4. Jang HD, Lee SJ, Park JM. Phacoemulsification with perfluorocarbon liquid using a 23-gauge transconjunctival sutureless vitrectomy for the management of dislocated crystalline lenses. Graefes Arch Clin Exp Ophthalmol 251:1267-1272 (2013).

5. Cauchi P, Azuara-Blanco A, McKenzie J. Corneal toxicity and inflammation secondary to retained perfluorodecalin. American Journal of Ophthalmology 140:322-323 (2005).

6. Inoue M, Iriyama A, Kadonosono K, Tamaki Y, Yanagi Y . Effects of perfluorocarbon liquids and silicone oil on human retinal pigment epithelial cells and retinal ganglion cells. Retina 29:677-681(2009).

7. Ho LY, Walsh MK, Hassan TS. 25-Gauge pars plana vitrectomy for retained lens fragments. Retina 30:843-849 (2010).

8. Barthelmes D, Alexander S, Mitchell P, Chandra J. Hybrid 20/23-gauge pars plana vitrectomy for retained lens fragments after cataract surgery. Retina 32:1749-1755(2012).

9. Smiddy WE, Guererro JL, Pinto R, Feuer W. Retinal detachment rate after vitrectomy for retained lens material after phacoemulsification. Am J Ophthalmol 135:183-187(2003).

10. Agarwal A, Narang P, A Kumar D, Agarwal A. Clinical outcomes of sleeveless phacotip assisted levitation of dropped nucleus. Br J Ophthalmol 98:1429-1434(2014).

11. Chiang A, Garg SJ, Alshareef RA, Pitcher JD 3rd, Hu AY, Spirn MJ, Hsu J, Lane RG, Regillo CD, Ho AC, Schwartz SD. Removal of posterior segment retained lens material using the OZil phacoemulsification handpiece versus Fragmatome during pars plana vitrectomy. Retina 32:2119-2126(2012).

12. Watanabe A, Tsuzuki A, Arai K, Gekka T, Tsuneoka H. Treatment of Dropped Nucleus with a 27-Gauge Twin Duty Cycle Vitreous Cutter. Case Rep Ophthalmol 7:44-48(2016).

13. Lin Z, Chen Y, Gao S, Zhong Y, Shen X. Surgical removal of submacular perfluorocarbon liquid with a 38-gauge flexible cannula combined with internal limiting membrane peeling and intravitreal air tamponade: a case series. BMC Ophthalmol 18:132 (2018). 
14. De Cillà S, Alkabes $M$, Radice $P$, Carini E, Mateo C. Direct transretinal removal of subfoveal perfluorocarbon liquid: the role and timing of internal limiting membrane peeling. Eur J Ophthalmol 27:249-252 (2017).

15. Yamane S, Sato S, Maruyama-Inoue M, Kadonosono K. Flanged Intrascleral Intraocular Lens Fixation with Double-Needle Technique. Ophthalmology 124:1136-1142(2017).

16. Holladay JT. Proper method for calculating average visual acuity. J Refract Surg 13:388-391(1997).

17. Schulze-Bonsel K, Feltgen N, Burau H, Hansen L, Bach M . Visual acuities "hand motion" and "counting fingers" can be quantified with the Freiburg visual acuity test. Invest Ophthalmol Vis Sci 47:1236-1240(2006).

18. Grover S, Fishman GA, Anderson RJ, Tozatti MS, Heckenlively JR, Weleber RG, Edwards AO, Brown J Jr. Visual acuity impairment in patients with retinitis pigmentosa at age 45 years or older. Ophthalmology 106:1780-1785(1999).

\section{Figures}
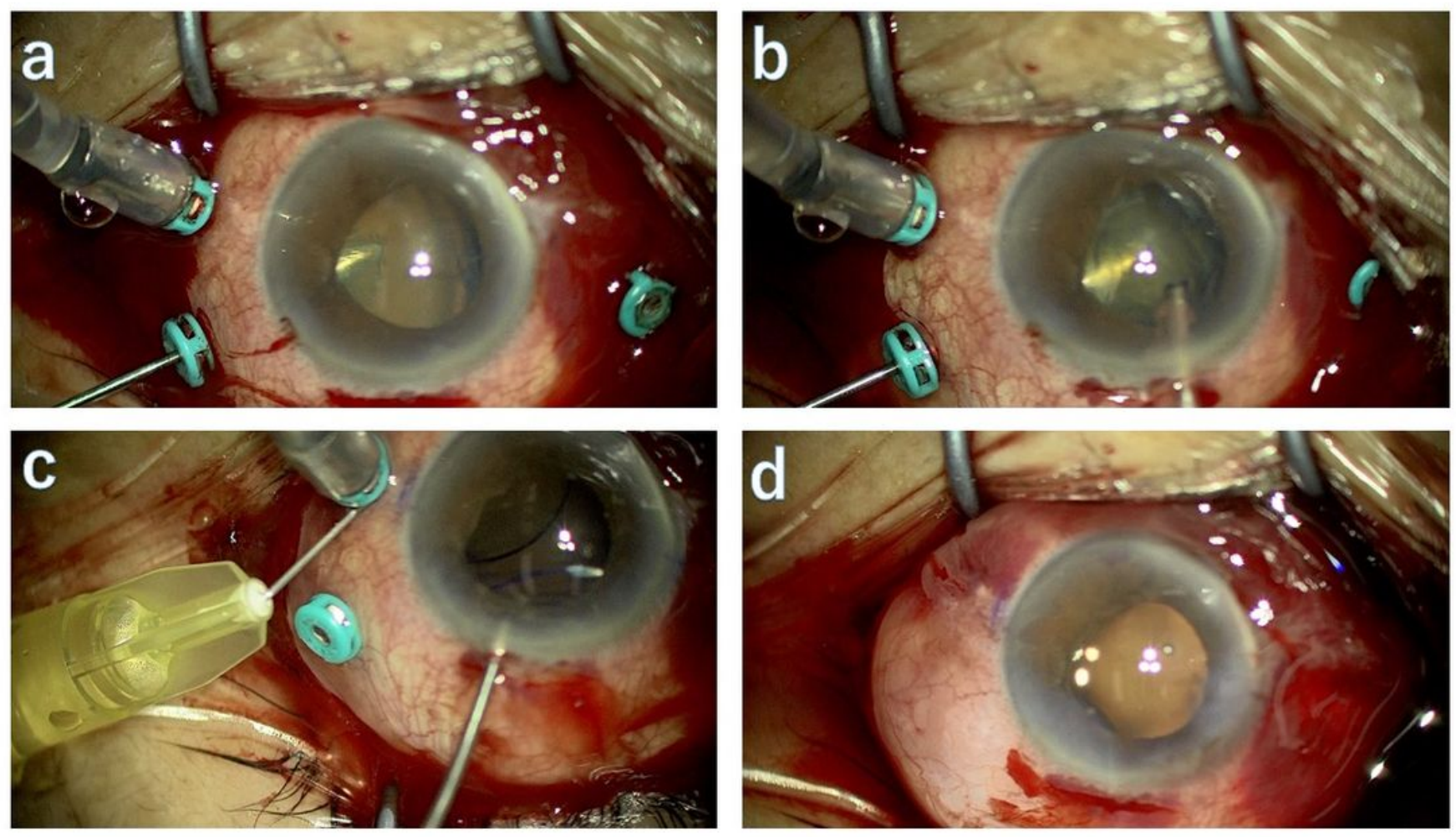

\section{Figure 1}

Kebab technique in a case of poor mydriasis. a: The dropped nucleus is lifted up from the retina to just deep to the iris. b: Phacoemulsification is possible under the iris as the lens is bonded to the bipolar pencil. c: Double-needle technique can be performed even in cases of poor mydriasis. d: By applying the kebab technique and the double-needle technique together, sutureless surgery is possible. 

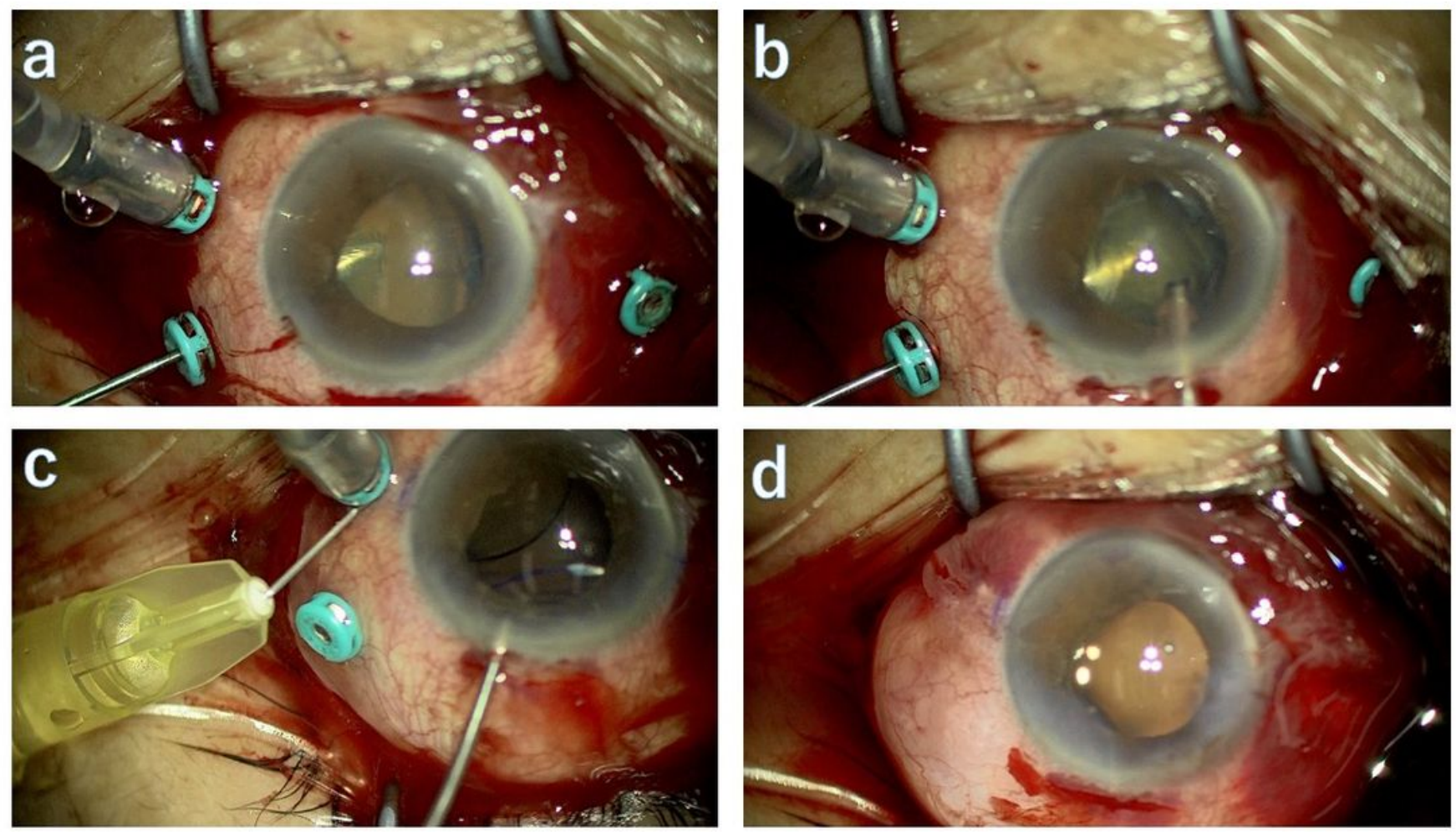

\section{Figure 1}

Kebab technique in a case of poor mydriasis. a: The dropped nucleus is lifted up from the retina to just deep to the iris. b: Phacoemulsification is possible under the iris as the lens is bonded to the bipolar pencil. c: Double-needle technique can be performed even in cases of poor mydriasis. d: By applying the kebab technique and the double-needle technique together, sutureless surgery is possible.
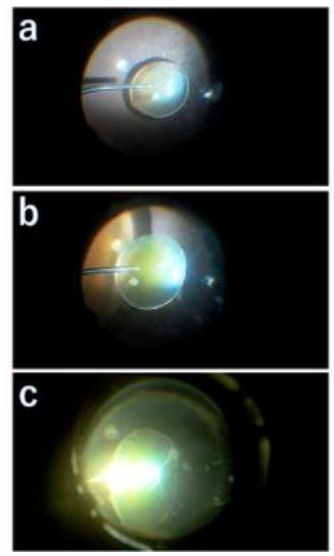
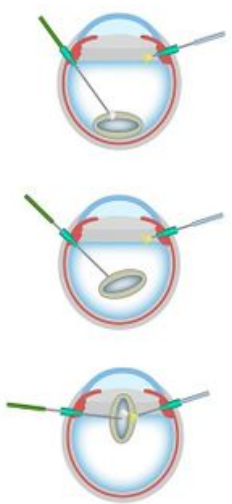
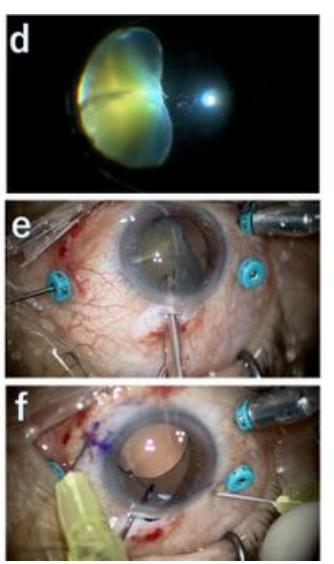

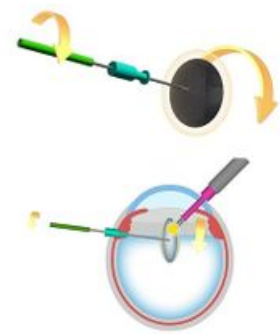

Figure 2

Kebab technique to remove the dropped nucleus. a: A bipolar pencil touches the nucleus slightly, and surface coagulation is performed briefly. b: The trapped nucleus is lifted up from the retina by the bipolar pencil. c: The bipolar pencil recoagulates the lifted nucleus assisted by an endilluminator. $\mathrm{d}$ : The bond becomes stronger, allowing the nucleus to be fully controlled by the bipolar pencil. e: The lifted nucleus can then undergo phacoemulsification with complete control of its rotation. f: After emulsifying the nucleus, the IOL is affixed by Yamane's double-needle technique as necessary. 


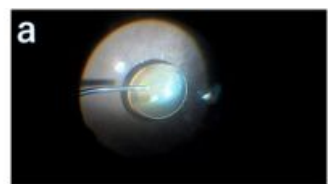

b

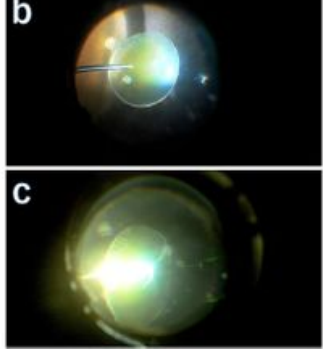

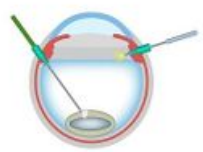
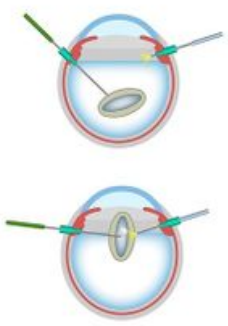
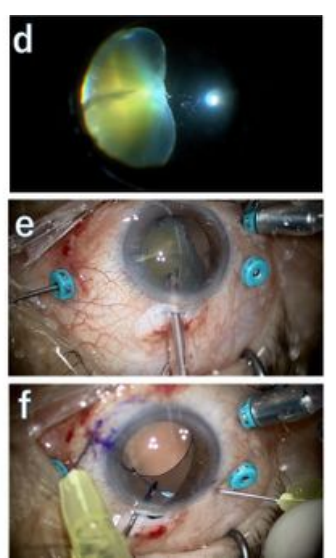

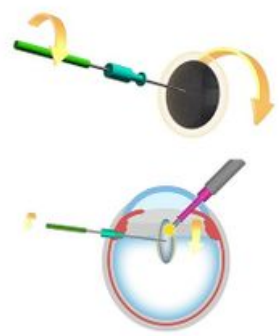

Figure 2

Kebab technique to remove the dropped nucleus. a: A bipolar pencil touches the nucleus slightly, and surface coagulation is performed briefly. b: The trapped nucleus is lifted up from the retina by the bipolar pencil. c: The bipolar pencil recoagulates the lifted nucleus assisted by an endilluminator. $\mathrm{d}$ : The bond becomes stronger, allowing the nucleus to be fully controlled by the bipolar pencil. e: The lifted nucleus can then undergo phacoemulsification with complete control of its rotation. f: After emulsifying the nucleus, the IOL is affixed by Yamane's double-needle technique as necessary. 